\title{
CIDADE E NATUREZA: UMA ESPECIFICIDADE NO MODO DE VIDA AMAZÔNIDA
}

\author{
Cleide de Souza ${ }^{1}$ \\ Voyner Ravena-Cañete ${ }^{2}$ \\ Introdução
}

A Amazônia congrega um "mundo" dentro de si. Marcada por um mosaico de casos diferenciados, tem, no formato de suas cidades, uma peculiaridade a mais. Tapauá, município situado no médio rio Purus, constitui-se em um desses modelos sui generis. Localizada parcialmente dentro do rio, já que parte das residências que compõe a cidade refere-se a flutuantes situados dentro do curso d'água, Tapauá apresenta, ainda, outras peculiaridades, como a restrição ao crescimento e uso da terra na sede municipal.

Tapauá se difere de todas as demais cidades do contexto da bacia do rio Purus. Representando a terceira maior em extensão territorial do país e a quinta maior do mundo, enquanto unidade municipal, com $89.326,6 \mathrm{~km}^{2}$, enfrenta uma limitação no uso da terra, principalmente na área urbana do município. Esse quadro se perfila em decorrência do bioma específico presente nesse município e da gestão diferenciada dos seus recursos naturais.

Conhecida como área sazonalmente inundada, a várzea congrega um leque de atividades socioeconômicas que permitem ao habitante uma multiplicidade de afazeres realizados em quatro períodos cíclicos do rio (seca, cheia, vazante e enchente). Esta sazonalidade imprime uma mobilidade à população para a garantia de sua reprodução social, econômica e cultural, impondo a esses moradores um modo de vida regido pelo tempo ecológico ${ }^{3}$. Algumas considerações sobre esse ciclo devem ser aqui mencionadas.

No período em que o rio seca, permite que as atividades agrícolas como o plantio e a pesca ocorram na praia e no igapó, respectivamente. Quando está enchendo, a atividade se concentra no plantio da roça de várzea e na colheita da roça de praia; a pesca ocorre no rio. Durante a cheia, se realiza a roça de terra firme e se pesca no lago. No início da vazante, se prepara o terreno para a roça de várzea e a pesca volta para o rio. Paralelamente ao trabalho agrícola e de pesca, são desenvolvidas as atividades

\footnotetext{
${ }^{1}$ Universidade Federal do Pará, Brasil.

${ }^{2}$ Universidade Federal do Pará, Brasil.

${ }^{3}$ Huguenin (2005: 2) define este termo da seguinte maneira: "É o universo natural seu relógio e calendário. A artificialidade das horas, dos minutos e dos segundos derrete-se na interação circular da cultura".
} 
extrativistas de coleta de castanha-do-Pará, andiroba, madeira e, ainda, uma minoria da população faz extração do látex. Assim, esta dinâmica do rio pode ser visualizada no quadro 1.

\begin{tabular}{|c|c|c|c|c|c|c|c|c|c|c|c|c|}
\hline Meses & Jan & Fev & Mar & Abr & Mai & Jun & Jul & Ago & Set & Out & Nov & Dez \\
\hline Ciclo do rio & \multicolumn{2}{|c|}{ Enchendo } & \multicolumn{3}{|c|}{ Cheia } & \multicolumn{3}{|c|}{ Vazante } & \multicolumn{3}{|c|}{ Seca } & Enchendo \\
\hline Pesca & \multicolumn{2}{|c|}{ Rio } & \multicolumn{3}{|c|}{ Igapó } & \multicolumn{3}{|c|}{ Lago } & \multicolumn{4}{|c|}{ Rio } \\
\hline Agricultura & \multicolumn{2}{|c|}{ Várzea } & \multicolumn{3}{|c|}{ Terra firme } & \multicolumn{3}{|c|}{ Várzea } & \multicolumn{3}{|c|}{ Praia } & Várzea \\
\hline Extrativismo & \multicolumn{2}{|c|}{ Castanha } & \multicolumn{3}{|c|}{ Castanha e látex } & \multicolumn{3}{|c|}{ Látex e andiroba } & \multicolumn{4}{|c|}{ Látex } \\
\hline
\end{tabular}

Quadro 1: Atividades desenvolvidas de acordo com a dinâmica do rio Purus. Fonte: Trabalho de campo (Setembro/2006).

A maior parte das terras do município constitui-se em áreas de várzea e abrange 4 Unidades de Conservação, assim classificadas: FLONA - Floresta Nacional de Balata-Tufari, RDS- Reserva de Desenvolvimento Sustentável Piagaçú-Purus, APA - Área de Proteção Ambiental Lago Ayapuá e REBIO - Reserva Biológica Abufari. Concentra uma variedade significativa de recursos naturais e, ainda, a maior quantidade de quelônios do estado, o que motivou a criação da Reserva Biológica Abufari, considerada a mais importante do país no que se refere a sua dimensão e peculiaridade envolvendo flora e fauna.

Além da várzea, o município também possui terra firme, caracterizada como área de terra alta, permanentemente seca. Situa-se distante da margem do rio, dificultando o acesso no período em que o rio seca. Nessas áreas localizam-se os castanhais, seringais, madeiras de lei, matas virgens e lagos piscosos, agregando alto valor econômico à área. Esse ambiente permite um tipo de habitação específica de casas sobre o rio, chamada localmente de flutuante.

Para a população residente da sede municipal, morar no flutuante representa o acesso à cidade, mantendo integração direta com o rio. Para o morador, esse tipo de habitação se apresenta como o ambiente de trabalho, de lazer e de locomoção, dada a imensa extensão territorial e distanciamento para o meio rural. Desse modo, a escolha pelo flutuante faz parte da dinâmica socioambiental que marca a vida do vargeiro ${ }^{4}$. A localização afastada da influência das grandes cidades, sendo Manaus a mais próxima,

\footnotetext{
${ }^{4}$ Esta categoria, segundo Lima e Alencar (2001), refere-se à autodenominação do morador da várzea.
} 
distante $769 \mathrm{~km}$ por via fluvial, demandando, aproximadamente, quatro dias de viagem em barco motor, estabelece para Tapauá uma dinâmica na relação cidade/campo por meio de um modo de vida semelhante entre os moradores dessas duas áreas, a priori, com um modo de vida diferenciado.

Considerando o tamanho do território, a predominância da várzea, o número de Terras Indígenas e Unidades de Conservação, Tapauá se constitui um cenário impar dentre os municípios que compõem a sub-bacia do Purus. Justificando, assim, a escolha desse município como lócus de estudo.

\section{Procedimentos Metodológicos}

O Município de Tapauá, pertencente ao Estado do Amazonas, na microrregião do Purus ${ }^{5}$. Distante $450 \mathrm{~km}^{2}$ em linha reta e $1.228 \mathrm{~km}^{2}$ por via fluvial de Manaus, capital do estado.

Sua extensão territorial totaliza $89.324 \mathrm{~km}^{2}$, colocando-o como o terceiro maior município do país e o quinto maior do mundo em extensão territorial. No Brasil, perde apenas para Barcelos, no mesmo estado, que é o segundo maior, com 122.572,7 km², e para Altamira, no estado do Pará, o maior município do mundo em extensão territorial, com 160.755,0 km². Embora Tapauá apresente uma das maiores extensões territoriais, há uma dificuldade no uso desse espaço para assentamentos humanos.

O método utilizado para esta pesquisa consistiu em um estudo de caso extraído de um cenário maior. O resultado obtido no projeto de pesquisa Gestão das Águas na Amazônia ${ }^{6}$ permitiu eleger Tapauá como a mais distinta e peculiar cidade nesse contexto, como já exposto, passível de um olhar mais específico. Nesse sentido, se optou pelo "estudo de caso" por entender que este método possibilita a investigação de fenômenos contemporâneos passíveis de análise mais aprofundada, critérios estes apontados por Yin (2005).

\footnotetext{
${ }^{5}$ Compõem essa Microrregião os municípios de Canutama, Lábrea e Tapauá.

6 “Gestão das Águas na Amazônia: peculiaridades e desafios no contexto sócio-político regional da bacia do rio Purus", projeto financiado pelo edital 048/2005 CNPq-PPG7, 2006-2008 e posteriormente desdobrado com o financiamento da Fundação Instituto para o Desenvolvimento da Amazônia FIDESA, 2008-2010.
} 
Trata-se de uma abordagem quali-quantitativa (Minayo, 1996). Os procedimentos utilizados para a coleta de dados consistiram em dois momentos distintos: levantamento de dados secundários e trabalho de campo, realizados conforme descrito a seguir.

Os dados secundários foram levantados junto às instituições públicas e não governamentais, objetivando tecer um perfil contextual de Tapauá. Para isso, se buscaram informações referentes à população, como número de habitantes residentes na cidade e no campo; sexo, faixa etária e, ainda, sobre a produção agrícola municipal, disponíveis no Instituto Brasileiro de Geografia e Estatística (IBGE).

Com relação aos dados de cunho ambiental, como tamanho e distribuição da área, buscaram-se dados no Instituto Brasileiro do Meio Ambiente e dos Recursos Naturais Renováveis (Ibama). No Ministério do Meio Ambiente (MMA), a quantidade, localização e finalidade de Unidades de Conservação existentes no município foram averiguadas. Outros órgãos acessados referem-se à Fundação Nacional do Índio (FUNAI) e à Fundação Nacional de Saúde (Funasa), para levantamento de número e localização de Terras Indígenas.

Com objetivo de quantificar as atividades de práticas tradicionalmente rurais exercidas por moradores da cidade, como pesca, roça e extrativismo, levantou-se junto aos sindicatos de produtores rurais e associação de pescadores o desenvolvimento destas atividades por quem reside na cidade.

Quanto às informações referentes aos serviços públicos como infraestrutura, equipamentos urbanos disponíveis às populações das áreas urbanas e rurais, se buscaram, na prefeitura e secretarias municipais, dados mais detalhados.

A pesquisa de campo para coleta de dados primários caracterizou-se como a mais importante, dadas as especificidades que o campo carrega, sendo realizada com um período de permanência de 30 dias na cidade de Tapauá, AM.

$\mathrm{O}$ instrumento de coleta consistiu em um questionário, contendo perguntas abertas e fechadas. A técnica utilizada foi pesquisa por "cluster" 7 , com o levantamento total dos 7 bairros que foram divididos em quadras, representando cada quadra como um cluster, totalizando 100 clusters, o que, em termos percentuais, representa dez por

\footnotetext{
${ }^{7}$ A definição de Cluster pode ser encontrada no artigo: Marques, J; Souza, C. Cluster como instrumento estratégico de regeneração urbana sustentável. Cad. de Pós-Graduação em Arquit. e Urb. São Paulo, v.4, n.1, p. 59-72, 2004.
} 
cento dos domicílios permanentes ${ }^{8}$ na cidade, segundo o IBGE, que no censo demográfico do ano de 2000 contabilizou 1000 domicílios. Em cada um destes clusters aplicou-se um questionário, com escolha aleatória do domicílio. Uma pessoa era eleita a responder, preferencialmente, um dos cônjuges e, na ausência destes, um integrante maior de idade. Assim, esse instrumento possibilita abranger informações referentes a todos os membros do domicílio.

A utilização de perguntas fechadas decorreu da necessidade de obtenção de dados quantitativos que expressassem a realidade local, de forma a representá-la em quadros. Os dados sistematizados possibilitam uma caracterização do grupo familiar, do número de habitantes no domicílio, estado civil, sexo, faixa etária, naturalidade, ocupação, renda, escolaridade e informações sobre a saúde nos últimos 12 meses. Essa escolha se pautou na compreensão de que "a informação que não pode ser diretamente visualizada a partir de uma massa de dados, poderá sê-lo se tais dados sofrerem algum tipo de transformação que permita uma observação de outro ponto de vista" (Regnier; Falcão, 2002).

Quanto às informações qualitativas, estas foram coletadas por meio de entrevistas semiestruturadas, possibilitando uma interação com o entrevistado de maneira mais espontânea, de forma a atender finalidades exploratórias, com maior aprofundamento, principalmente no que se refere às questões do cotidiano e modo de vida de diferentes atores presentes em espaço socialmente distinto, e, ainda, por entender que este procedimento possibilita detalhar as questões mais específicas, visto que o entrevistado pode discorrer livremente sobre o tema investigado (Bourdieu, 1983).

Assim, os questionamentos se propuseram a entender a história de vida; origem de moradia; o motivo da mudança para a cidade; as atividades desenvolvidas, tais como plantação de hortaliças, criação; presença de parentes na cidade; relação com o campo e a frequência e o motivo dos deslocamentos. Foi possível perceber, ainda, que esses moradores elegem o que mais gostam e o que menos gostam na cidade, bem como a pretensão quanto à permanência ou retorno para o campo. A descrição dos moradores que consideram uma cidade ideal para se viver também foi questionada, com intuito de compreender a percepção de cidade e urbano desses habitantes. Informações como hábito alimentar, horários em que costumam dormir e acordar, religião e preferências

\footnotetext{
${ }^{8}$ Definição utilizada pelo IBGE para os domicílios particulares com fins residenciais.
} 
por lazer foram levantadas, buscando identificar a predominância de práticas tipicamente rurais.

Outra técnica empregada consistiu na observação dos fatos, também denominada de observação assistemática. Esta técnica possibilita obter um contato mais próximo com a realidade a partir do registro de práticas cotidianas sem meios técnicos de controle, priorizando anotações em diário de campo. Busca, desta forma, identificar fenômenos que se processam no espaço urbano não perceptível no contato formal, mas que necessitam de uma aproximação pouco direcionada para explorar o universo investigado (Lakatos, 1996). Assim, além do questionário aplicado, foi estabelecida uma permanência maior no domicílio, de forma que se construísse um diálogo informal com os moradores.

Através da metodologia qualitativa descrita a pesquisa descreve o cotidiano dos moradores da cidade em seus afazeres econômicos, socioambientais e culturais relacionados ao uso dos recursos naturais. Enfoca o modo de vida, demonstrando a prática de ruralidade vivenciada no espaço urbano que constitui a cidade e a interação permanente destes com o meio rural.

Do ponto de vista teórico a pesquisa se pautou na discussão sobre cidade, urbano e rural. Buscando compreender rural e urbano a partir do modo de vida de seus habitantes, usou como aporte teórico Wirth (1987) que se utiliza da categoria urbanismo para discorrer sobre o modo de vida de quem reside na cidade. Neste sentido, urbano e rural serão analisados não somente pela presença/ausência de equipamentos urbanos, mas também pelo cotidiano de seus moradores expressos por meio de um modo de vida resultante da interação com o meio rural.

\section{Tapauá enquanto especificidade de cidade}

Aparentemente, Tapauá não se difere da maioria das pequenas cidades com população inferior a 20 mil habitantes existentes no país. Pequena, pacata, com baixa densidade populacional, pouco urbanizada, com pessoas simples. Todavia, ao lançar um olhar mais centrado no que ela tem de específico, pode-se averiguar uma diversidade populacional que envolve índios, ribeirinhos, seringueiros, pescadores e madeireiros interagindo em um ambiente com riqueza de recursos naturais próprios do ecossistema de várzea. 
A vida na várzea não significa somente compartilhar os recursos naturais, mas compreender as especificidades que permeiam o habitar, o fazer agrícola e a dinâmica de deslocamento, conhecimento e interação ao ciclo da natureza, mas no caso de Tapauá reflete o modo de vida de seus habitantes por meio da acentuada prática predominantemente rural imbricada no meio urbano.

A existência de muitas Terras Indígenas (TI’s) e de Unidades de Conservação (UC's) agrega uma peculiaridade a mais aos moradores de Tapauá, tanto para os que vivem no meio urbano como no rural. Trata-se da restrição ao uso do território pela população. No entorno da cidade, a Terra Indígena denominada São João, pertencente à etnia Apurinã, limita, como já mencionado, com o perímetro urbano, ocasionando uma incapacidade de sua expansão em função da normativa que rege as TI's. Este quadro impossibilita, definitivamente, o crescimento da cidade, pelo menos horizontalmente, embora, na prática, se saiba que não é possível frear ou impedir o crescimento de uma cidade, visto que o aumento de natalidade é continuo, e, sobretudo, se levar em conta o crescimento urbano, fenômeno decorrente do aumento populacional em todo o mundo (UNFPA, 2005).

Por outro lado, as UC's na área rural dificultam o acesso do morador ao uso da terra, para trabalhar e até mesmo para residir. Esta condição acaba expulsando-o para a cidade, onde razões similares a impedem de abrigá-lo. Consequentemente, este cenário que se forma a partir das restrições de acesso e uso da terra, cria uma mobilidade que não significa apenas o deslocamento demográfico, mas, sobretudo, uma dinâmica instalada no modo de vida, envolvendo trabalho, moradia e apropriação do tempo ecológico a partir da sazonalidade ambiental.

Embora este texto não objetive analisar este quantitativo de áreas preservadas, se faz necessário mencionar que a criação destas resulta de um modelo advindo dos E.U.A, cuja realidade socioambiental não se aplica ao Brasil, tampouco à Amazônia. Enquanto, segundo Medeiros (2003), Unidades de Conservação constituem espaços territorialmente conservados, cujo objetivo é preservar os recursos naturais e/ou culturais a eles associados, Santilli (2003: 3), conhecedora da interação estabelecida entre homem e natureza, aponta que "já há diversos estudos mostrando que são as práticas, inovações e conhecimentos desenvolvidos pelos povos indígenas e populações tradicionais que conservam a diversidade biológica de nossos ecossistemas, principalmente das florestas tropicais". E, assim, considera que: 
Mais do que um valor de uso, os recursos da diversidade biológica tem, para essas populações, um valor simbólico e espiritual: os 'seres' da natureza estão muito presente na cosmologia, nos símbolos e em seus mitos de origem. A produção de inovações e conhecimento sobre a natureza não se motiva apenas por razões utilitárias, como por exemplo, descobrir a propriedade medicinal de uma planta para tratar uma doença ou domesticar uma planta-selvagem para cultivá-la e utilizá-la na alimentação. Transcendem a dinâmica econômica e permeiam o domínio das representações simbólicas e identitárias. (Santilli, 2003: 3).

Observa-se, portanto, que não é possível dissociar os recursos naturais dos atores que os conhecem e se utilizam deles, haja vista que ambos integram, simbolicamente, o mesmo hábitat. Entretanto, além da restrição legal, as poucas áreas disponíveis em Tapauá são áreas de várzea, inundadas permanentemente o que impossibilita a construção de moradias, como consta na figura 01 .

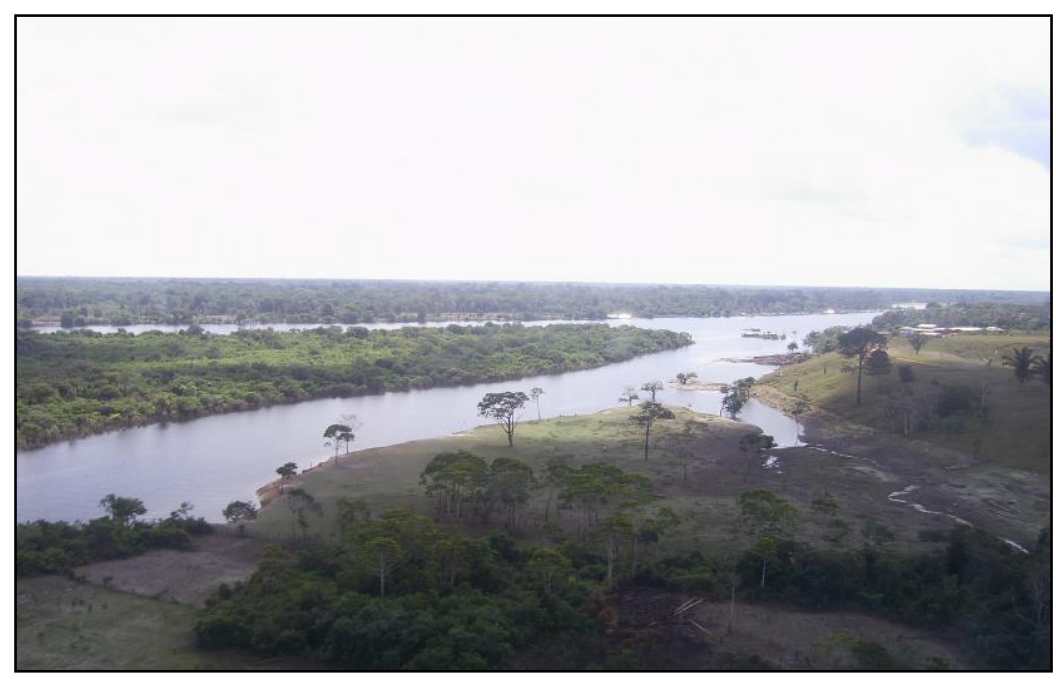

Figura 1: Área de várzea no entorno da cidade de Tapauá.

Fonte: Pesquisa de campo (2008).

Assim, diante da impossibilidade de ampliação do perímetro urbano, a cidade acaba se expandindo para dentro do rio, formando um novo desenho a partir do saber local. A relação estabelecida anteriormente no ambiente de várzea torna complexo distinguir o modo de vida dos que vivem na cidade aos do meio rural, em função da similaridade presente nos costumes e afazeres cotidianos. A figura a seguir ilustra a expansão da cidade para dentro do rio. 


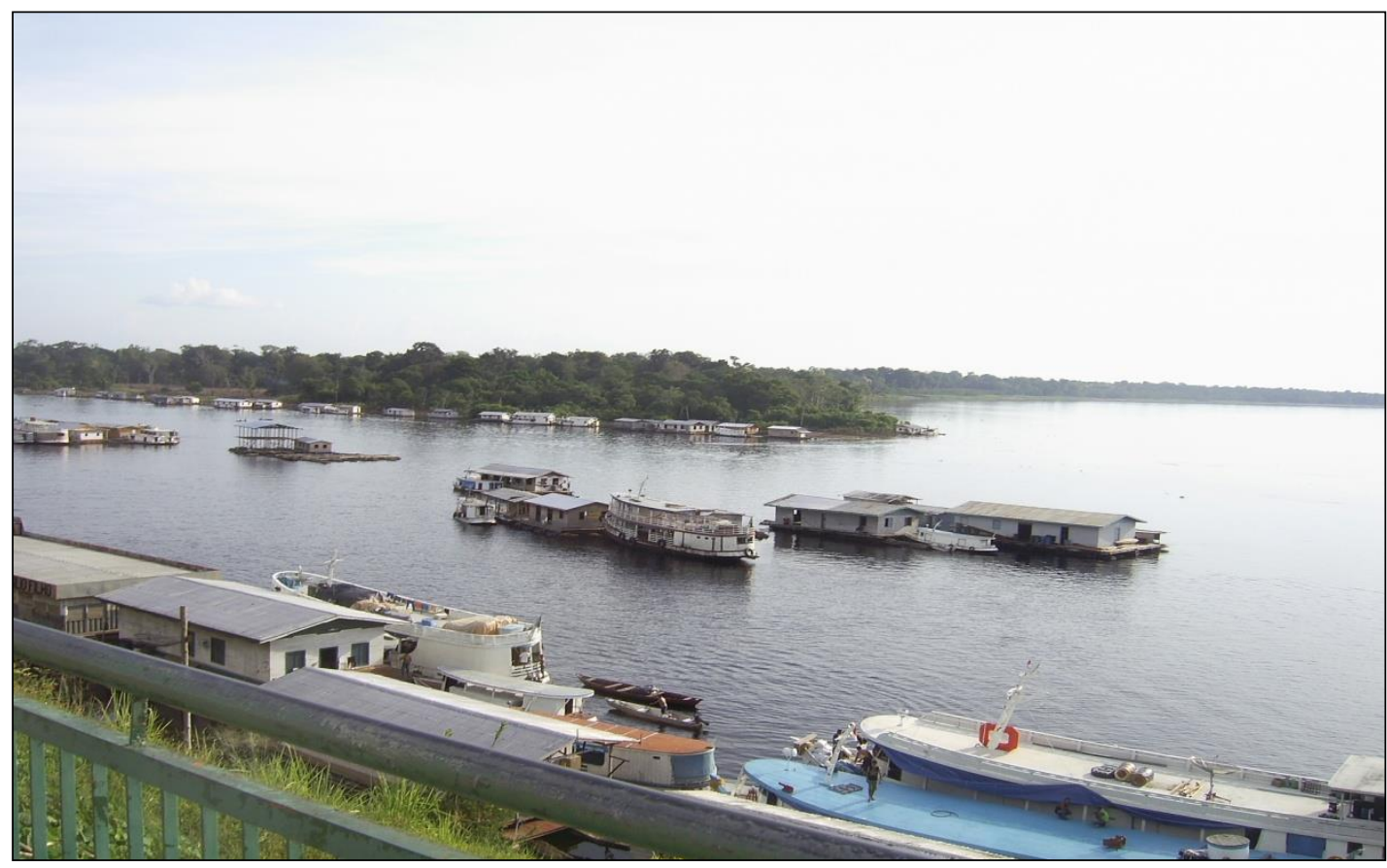

Figura 2: Imagem de parte da cidade situada sobre o rio Purus.

Fonte: Trabalho de campo (2008).

Esta complexidade se apresenta porque grande parte dos moradores provém do meio rural e neste a reprodução social incide no ambiente inundado que, em determinados períodos do ano, se confunde com o rio.

Contudo, esta parte da cidade que se forma sobre o rio ainda não foi incorporada ao planejamento urbano, embora seja vista, informalmente, como um bairro periférico, uma vez que é ocupado de forma desordenada, como ocorre em área de invasão de qualquer cidade. Por outro lado, a reprodução social dos demais habitantes da cidade se estabelece diretamente com a dinâmica do rio, podendo ser compreendida à luz da teoria de Wirth (1987), quando afirma que o urbanismo como modo de vida transcende o limite físico de uma cidade, haja vista que seus moradores carregam características da vida anterior e, se proveniente do meio rural, seu modo de vida o expressará.

No entanto, a ordenação deste lugar não é contemplada no plano diretor, em que estes moradores não são sequer mencionados. Observa-se que esta situação, por si só, representa uma incompatibilidade com a prática de gestão.

Em Tapauá, a constante migração dos moradores do meio rural para a cidade, juntamente com suas práticas cotidianas, permite confirmar a expansão do campo para a cidade, o inverso do que se convencionou chamar de completa urbanização. No entanto, esta realidade ainda vem sendo ignorada por muitos estudiosos da cidade em todo 
território brasileiro, dentre eles, Wanderley (2001), que analisa as mudanças no meio rural, denominando de novo rural ou ruralidade, atribuindo às suas mudanças o avanço da cidade sobre este, porém, há de se ponderar que as pesquisas desta autora se restringem apenas ao interior pernambucano. Todavia, o que este texto apresenta se refere às especificidades urbanas presentes nas pequenas cidades da Amazônia brasileira.

A literatura que versa sobre urbano e rural considera, em geral, o avanço da cidade para o campo. A tese defendida por Lefebvre (1991) aponta a expansão do urbano para o rural, ao prever a completa urbanização do campo, descartando a hipótese do avanço do campo para a cidade. Vale ressaltar que Lefebvre, ainda na década de 1970, realizou seus estudos sobre o processo da revolução industrial, em que países europeus já vivenciavam o avanço tecnológico, dominando os processos mecanizados.

Graziano da Silva (2001) compreende este "novo rural", interpretado por Wanderley, atribuindo-lhe a presença de serviços considerados urbanos que, por meio dos processos extensivos no meio rural, alteram a forma de trabalho. Deixa, assim, de ser especificamente voltado para a agricultura e extrativismo, para incorporar os serviços de turismo, hotelaria ou mesmo a atuação de pessoas provenientes do meio urbano. O autor toma como exemplo guardas ambientais, profissionais da saúde e da educação, que vão da cidade para o meio rural, onde há carência de pessoas qualificadas para estas atividades e consigo conduzem comportamentos próprios do meio urbano, como o modo de falar, de se vestir e até mesmo hábitos alimentares que podem influenciar o meio onde atuam.

Observa-se que estes estudos descartam a coexistência do rural com o urbano, visto que, quando há mudanças no meio rural, se atribui à chegada do urbano. Desta forma, torna-se bastante pertinente a crítica que Abramovay (2000) apresenta à aplicabilidade destas teorias para a empiria brasileira. O autor relata que, quando se faz menção às mudanças ocorridas no meio rural, elas se dão em decorrência da presença do urbano; por outro lado, as que ocorrem no meio urbano são compreendidas como uma complexidade que envolve somente o fenômeno urbano, descartando, assim, qualquer influência do rural.

Ao considerar esta vertente, tende-se a pensar que somente o urbano incide sobre o rural, não se analisando, inversamente, a predominância do rural no meio urbano. Embora haja pesquisas que apontem características de uma ruralidade no urbano, tais estudos pontuam apenas algumas similaridades. Vale lembrar Wirth (1987), que adverte 
para a impossibilidade de tratar o urbano e o rural como dois mundos opostos, visto que um influencia o outro.

\section{$O$ acesso à cidade - trajetórias rurais}

Embora o meio rural seja possuidor de uma diversidade e quantidade abundante de recursos naturais, em função do bioma e da dimensão territorial, o morador finda não fixando residência, devido à restrição ao uso desses recursos, o que representa um dos motivos que o impulsionam a mudar para a cidade. Essa mudança é feita em sua própria residência, chamada de flutuante, pelo fato de ser construído sobre o rio, o que possibilita sua locomoção.

É importante ressaltar que no meio rural a preferência por estas casas flutuantes ocorre porque há pouca terra disponível, além disso, a morada no ambiente de várzea se torna temporária, devido às constantes erosões no solo pelo processo de inundação, como descreve Lima; Alencar (2001). Esta especificidade local atribui ao morador uma dinâmica que lhe permite uma mobilidade no rio, dentro de sua própria residência. Assim, no processo de mudança, conduz sua casa, geralmente seu único patrimônio. Durante o percurso para a cidade, sobre o rio, lhe é permitida a execução do seu trabalho, seja na pesca ou na roça, devido à estreita relação mantida com a natureza durante todos os períodos cíclicos.

É importante mencionar que a mudança para a cidade se dá de forma sazonal, condicionada ao ciclo do rio, não ocorrendo no momento conveniente ao morador; se faz necessário que a maré não esteja tão seca e correndo em direção à cidade, para que o morador se mude na própria residência, ou seja, no flutuante, conduzido pelas águas.

Esta mudança pode levar dias em que a casa flutuante é transportada pelo rio. Durante este trajeto, o chefe de família desenvolve suas atividades econômicas, normalmente, indo para a roça, pescando e retornando ao final das tarefas para sua residência, onde quer ela esteja, sendo possível alcançá-la por canoa ou rabeta. Na maioria das vezes, se obtém o alimento no próprio flutuante, onde esposa e filhos geralmente pescam. No decorrer da noite, sem iluminação suficiente, encostam a casa às margens do rio, para que não seja atropelada por barco/motor, continuando a viagem no dia seguinte. 
Ao chegar à cidade, se depara com as dificuldades em construir assentamentos na área urbana delimitada pelo poder público. Por essa razão, opta pela permanência em seu flutuante, o que significa morar sobre o rio. Esta alternativa faz com que esse morador reproduza o ambiente vivido anteriormente na várzea, na área rural.

Em algumas situações, a mudança ocorre inesperadamente, por uma necessidade, sem um desejo prévio da família. Isto pode ser quando um membro da família adoece e precisa ser tratado na cidade; com a certeza do longo tempo para o tratamento e impossibilitado do afastamento da família, visto que esta atua coletivamente no sustento, se mudam para a cidade. Neste caso, se a maré não estiver favorável e a família dispor de recursos financeiros, a casa será conduzida por barco; do contrário, irá morar inicialmente com um parente ou conhecido até a condução ou construção de seu flutuante.

Dados de campo apontam a procedência dos que atualmente residem na cidade. Estes, em sua maioria, provêm da área rural do próprio município ou dos demais municípios que compõem a calha do Purus, mas sempre originários do próprio rio. Dos 100 domicílios em que foram aplicados questionários, apenas 7 famílias têm sua origem na cidade, embora seus antecedentes tenham sido do meio rural; as demais residiam no meio rural e mudaram com objetivo principal de acessar os serviços públicos, como saúde e educação.

Em função desta trajetória, hoje o morador da cidade mantém relação estreita com o meio rural por meio do trabalho na roça e na pesca, exercidos por muitos membros do grupo familiar, alguns de forma menos intensa, devido à ocupação em outra atividade no mercado formal ou informal na cidade, que lhe garante uma renda fixa. Para eles, o trabalho rural se concentra na produção de alimentos (farinha, peixe e caça), realizados aos finais de semana, mesmo que seja somente para o consumo. Assim, tal como em outras áreas do país:

Os pequenos proprietários e trabalhadores 'liberados' das relações tradicionais de produção ao invés de se dirigir, conforme o processo clássico, para as cidades e se assalariar em atividades urbanas, tendem a se ocupar em atividades rurais e urbanas e tornar-se uma força de trabalho sazonal dedicada tanto a atividades urbanas quanto primárias. (Limonad, 1999: 84). 
Como se vê, a relação da cidade com o campo ainda ocorre por meio do trabalho exercido por ambos no meio rural, mesmo os que moram na cidade. Além disso, as lembranças do rural estão vivas e são citadas com certo saudosismo ao se referirem à vida tranquila, sossegada e farta que tinham antes. Ao serem questionados sobre o que mais gostavam ou do que mais sentem falta, são incisivos em apontar os costumes relacionados ao ambiente natural, como a água, a terra, o rio, o vento e a tranquilidade que o espaço lhes garantia, dado o isolamento entre uma casa e outra no meio rural, conforme apresentado no quadro 2.

\begin{tabular}{|l|c|}
\hline \multicolumn{1}{|c|}{ Preferência } & Número de entrevistas \\
\hline Da tranquilidade, do silêncio & 19 \\
\hline De cuidar da terra, plantar, fazer roça, capinar & 11 \\
\hline De pescar, do rio, do lago e da praia & 17 \\
\hline Da comida, peixe fresco, caça & 11 \\
\hline Fartura & 11 \\
\hline Do ar, do clima, da mata e dos animais & 09 \\
\hline Passear/tomar banho & 03 \\
\hline Das pessoas & 02 \\
\hline O custo de vida é menor & 02 \\
\hline Não gosta & 15 \\
\hline Total & $\mathbf{1 0 0}$ \\
\hline
\end{tabular}

Quadro 2: Do que mais gosta do interior/meio rural. Fonte: Pesquisa de campo (2008).

Observa-se, portanto, que o morador destaca como preferência as atividades relacionadas com o rio. Este representa o lugar onde se realiza a atividade socioeconômica, pesca no rio, no lago e no igapó, passeios, tomar banho e praia.

As atividades festivas na cidade se referem também às atividades primárias, dentre elas se destacam a Festa da Castanha, comemoração ao fim de cada safra e a Festa do Pescador e Produtor, em agradecimento ao trabalho realizado. 


\section{O modo de vida e o cotidiano urbano/rural em Tapauá}

Descrever o cotidiano desses moradores requer compreender a dinâmica existente na relação permanente entre cidade e campo, visto que, mesmo depois que muda para a cidade, o trabalho rural é mantido. Com isso, o modo de vida que envolve o cotidiano dos moradores de Tapauá reflete uma prática relacionada diretamente com o meio rural. O horário em que estão habituados a dormir e a acordar está relacionado ao tempo ecológico, regido pela natureza, considerando que esta população realiza seus trabalhos obedecendo à sazonalidade do rio.

Percebe-se que muitos moradores costumam dormir às 19 horas se estendendo até às 23h30min. Quanto ao horário em que acordam, se dá a partir das duas horas, indo no mais, às sete horas, como representado no gráfico abaixo.

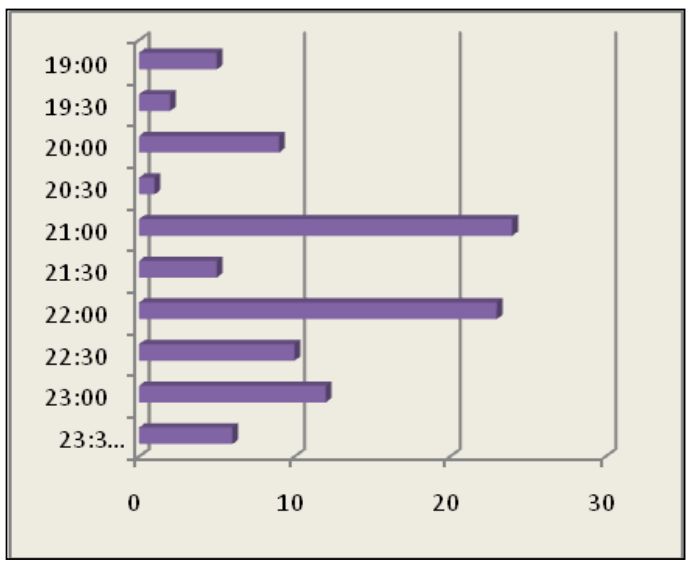

Figura 03: Horário em que costumam dormir. Fonte: Pesquisa de campo (2008).

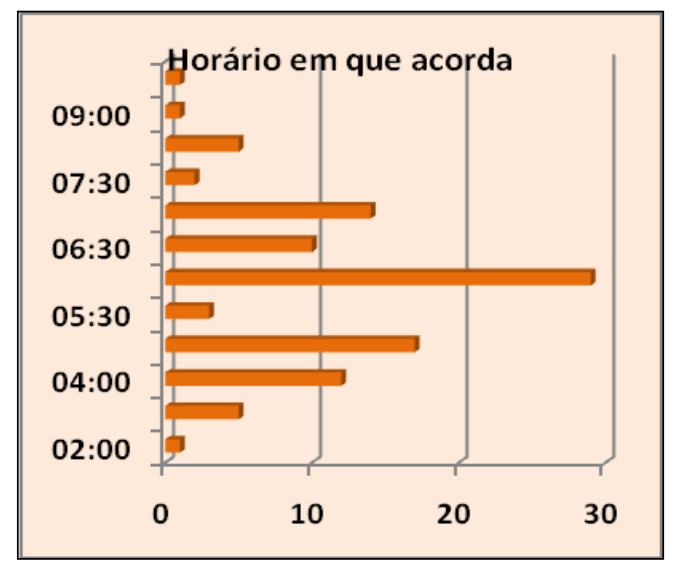

Figura 4: Horário em que costumam acordar. Fonte: Pesquisa de campo (2008).

Este horário em que o morador habituou acordar e dormir está relacionado às atividades socioeconômicas de caráter rural desenvolvidas de acordo com o ciclo do rio, sendo este o ambiente de moradia, locomoção e trabalho. Assim, no gráfico a seguir consta a atividade caracterizada como rural realizada por integrantes dos domicílios em que foi aplicado o questionário. 


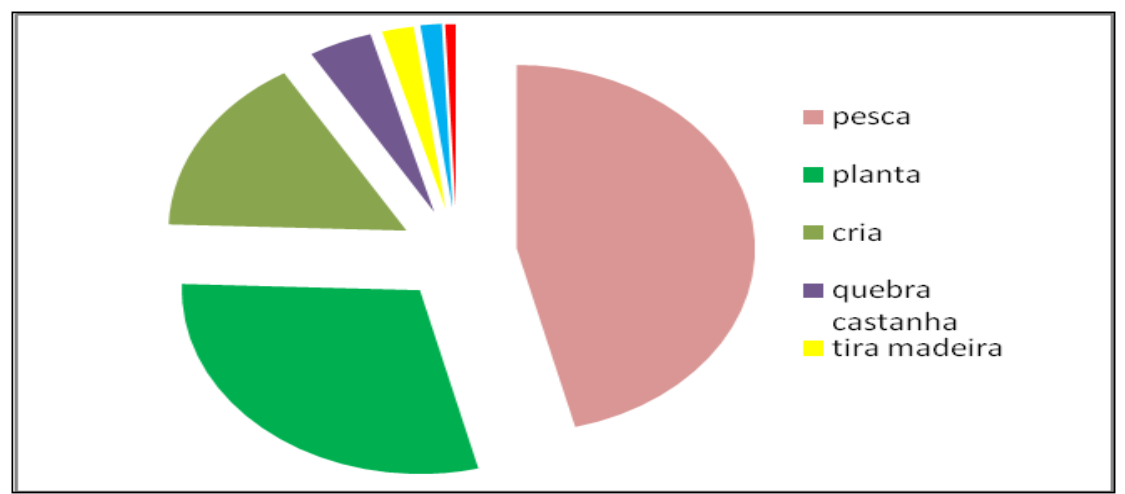

Figura 5: Atividade desenvolvida na área rural por moradores da cidade. Fonte: Pesquisa de campo (2008).

É importante informar que, além destas atividades, desenvolvem outras no mercado formal e informal, mas sempre culminando com as atividades rurais para prover a alimentação, auxiliados pelos demais membros do domicílio. Entretanto, a reprodução social destes moradores conflita com a política federal de proteção ambiental. Principalmente, na fixação dos assentamentos e restrição de determinadas áreas, fazendo com que o morador se mobilize para outros ambientes, mas sem abrir mão do modo de vida, que possibilita uma interação permanente com os recursos naturais.

Em razão da quantidade de áreas de conservação, os moradores realizam um longo percurso de uma localidade para outra, desde que não seja Unidade de Conservação ou Terra Indígena. Esta mobilidade se dá de acordo com os ciclos do rio. No entanto, a dinâmica que faz com que estes moradores se mobilizem sazonalmente não é suficiente para garantir sua sobrevivência. A ausência de serviços públicos finda forçando a ida para a cidade pela necessidade de acessá-los. Portanto, esta mudança, não representa um desejo maior pelo modo de vida urbano.

Diante da ausência destas políticas no meio rural, muitos recorrem à cidade para poder ter acesso à educação e à saúde, direitos que lhes são garantidos constitucionalmente, independentemente do lugar onde residem. A tabela 1 apresenta as razões pelas quais pessoas do campo foram morar na cidade, ficando evidente que não ocorreu por uma escolha ou simplesmente desejo de viver na cidade. 


\begin{tabular}{l|l} 
Mudou para a cidade (motivo) & $\begin{array}{l}\text { Número } \\
\text { entrevistas }\end{array}$ \\
\hline Para os filhos estudarem & 39 \\
\hline Já tinha familiares que moravam na cidade ou casou com alguém da cidade & 10 \\
\hline Para obter assistência à saúde & 08 \\
\hline Nasceu na cidade ou veio ainda criança & 08 \\
\hline Outros & 07 \\
\hline Conseguiu emprego/passou em concurso público & 05 \\
\hline Não informado & 05 \\
\hline Em busca de melhores condições de vida & 03 \\
\hline Perdeu um ente querido & 03 \\
\hline Houve algum desentendimento com outras pessoas & 03 \\
\hline Não tinha motor, isolamento, difícil locomoção. & 02 \\
\hline Não é violento & 02 \\
\hline Tudo era tudo muito caro & 02 \\
\hline Tinha vontade de viver na cidade & 01 \\
\hline Tem energia elétrica & 01 \\
\hline Na cidade é mais fácil vender o peixe & 01 \\
\hline Total & $\mathbf{1 0 0}$ \\
\hline
\end{tabular}

Tabela 1: Motivos que levaram pessoas do meio rural a optar pela cidade.

Fonte: Pesquisa de campo (2008).

Porém, morar na cidade não representa garantia de acesso a todos os serviços públicos. Em Tapauá, o citadino precisa se locomover a outra cidade maior e distante para acessar, por exemplo, uma agência bancária. Para o recebimento de recursos destinados à política social como o Programa Nacional de Fortalecimento da Agricultura Familiar (PRONAF), que garante um seguro aos pescadores durante o período de defeso do pescado, os pescadores necessitam viajar de barco durante seis dias, até a cidade de Manacapuru, onde se situa a instituição bancária responsável pelo pagamento desse seguro.

Pode-se averiguar que para facilitar o acesso às políticas públicas voltadas ao homem do campo, este necessita estar na cidade. Assim, os motivos que levam as pessoas da área rural a migrar para a cidade, dizem respeito, também, à busca por serviços considerados básicos. Os gestores que articulam as políticas públicas de atendimento às atividades primárias não viabilizam o trâmite que, no caso de Tapauá, sequer pode ser acessado, nem mesmo na cidade, sede do município. A falta de infraestrutura como saneamento básico se evidencia com a incidência de doenças epidêmicas, constantes na cidade e representadas abaixo, no figura 6 . 


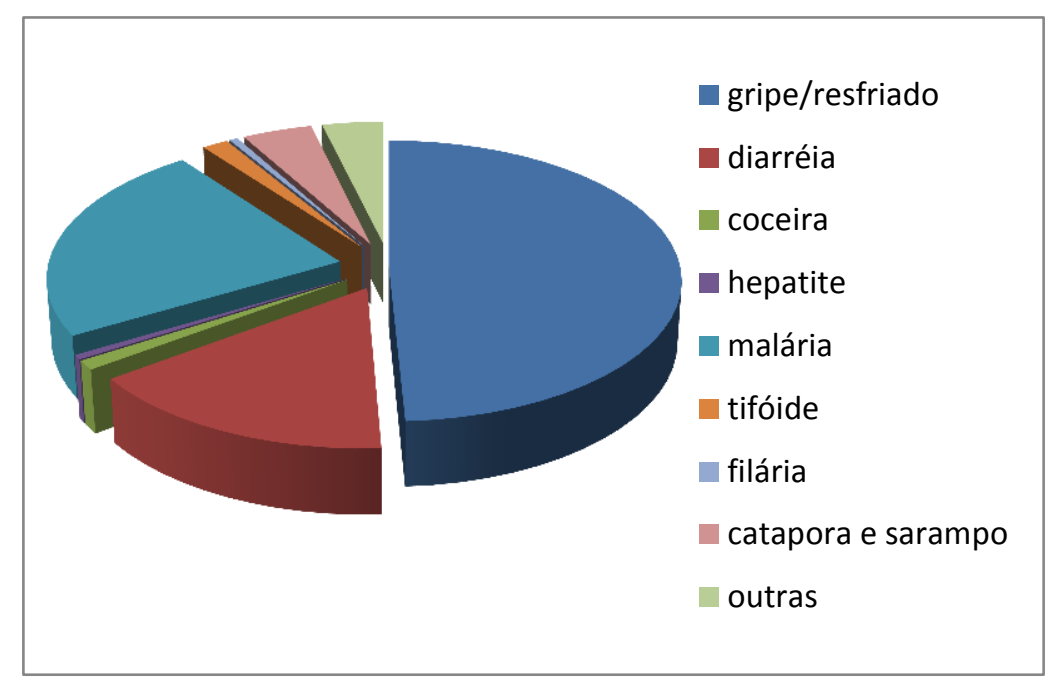

Figura 6: Doenças epidêmicas presentes na cidade.

Fonte: Pesquisa de campo (2008).

Como se observa, doenças como sarampo e catapora já erradicadas em grande parte do território nacional, ainda persistem em Tapauá. A filária, tifóide, hepatite, coceira e a diarréia são decorrentes da falta de saneamento, enquanto que a malária, própria de ambientes naturais, está presente na população dita urbana. Dentre estas, se destacam a gripe e resfriados ocasionados pela falta de atenção básica a saúde.

Portanto, os motivos pelos quais os moradores do meio rural mudam para a cidade não se referem à busca aos equipamentos considerados urbanos, representa a necessidade aos serviços públicos básicos que deveriam ser disponibilizado a toda população do município, independentemente da localização onde reside, pois se trata de um direito garantido constitucionalmente a todo cidadão brasileiro.

No entanto, a mudança para a cidade não representa alteração na forma de trabalho. As atividades antes realizadas na área rural permanecem, apenas o morador rural passa a residir no meio urbano. As atividades como agricultura, extrativismo, pesca e criação, são mantidas. A imagem a seguir evidencia a criação galinhas e cultivo de hortaliças na cidade, no próprio flutuante. 


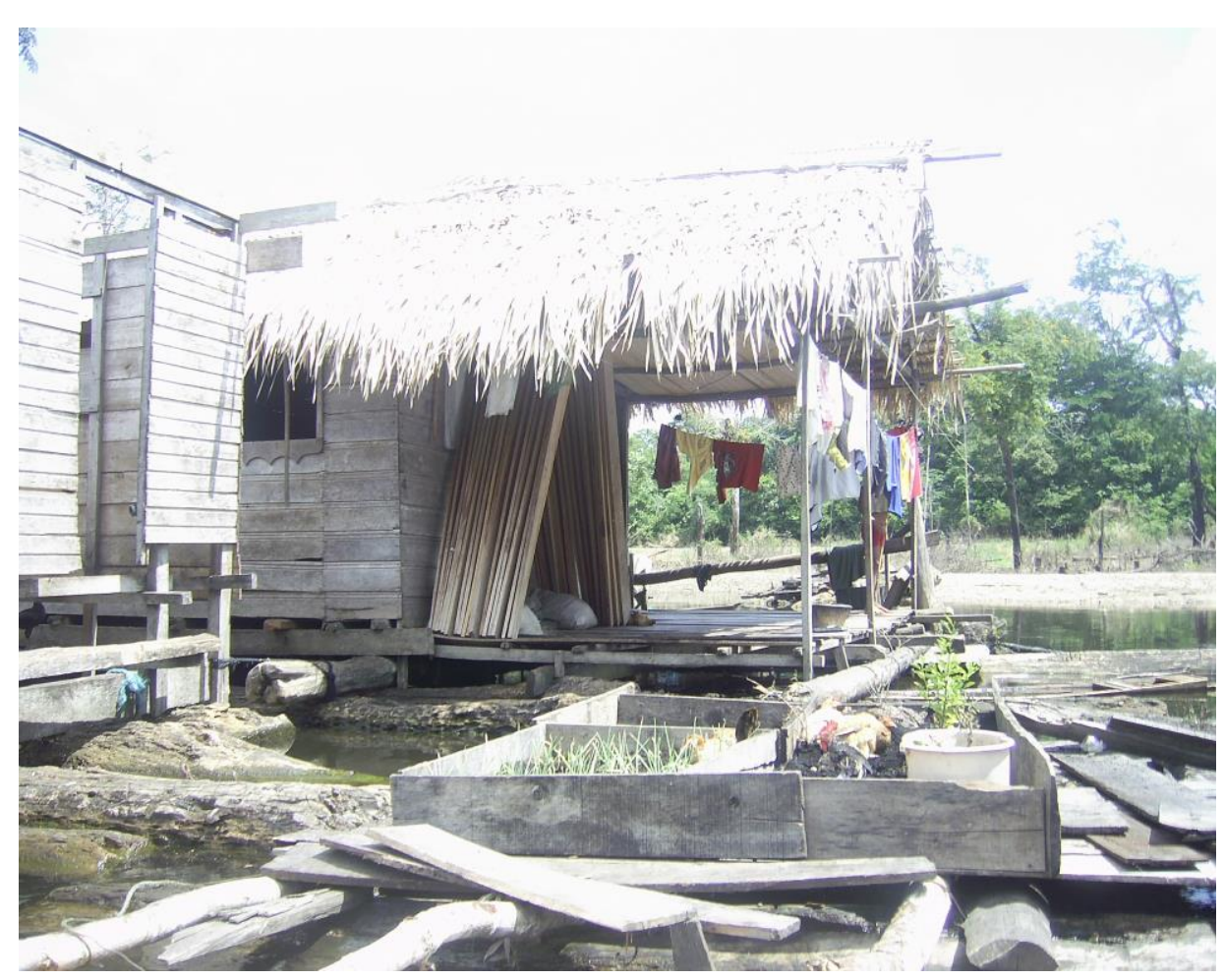

Figura 7: Cultivo de hortaliças em jiraus e criação de galinha no flutuante.

Fonte: Pesquisa de campo (2008).

A reprodução social destes atores ocorre tanto no meio urbano como no rural e representa uma dinâmica no uso do mesmo ambiente, ou seja, a várzea. Considerando que na cidade esses moradores não desprezam tais atividades, pode-se assim dizer que se trata de uma ruralidade, dado que as práticas e hábitos cotidianos permanecem os mesmos vivenciados em seu cotidiano fora do meio urbano. Assim, não foi o urbano que se expandiu para o campo e sim o rural que gerou a cidade, expresso no modo de vida de seus habitantes.

Nesse sentido, os moradores de Tapauá vivem práticas predominantemente rurais, que não se diferenciam com as do campo. Quando o morador se refere ao rural, destaca características tipicamente rurais, sente saudade da tranquilidade, do peixe fresco e quando aponta algo que não gosta, também está relacionado à natureza, como as pragas e o isolamento.

Diante deste cenário, pode-se dizer que Tapauá ainda agrega características da pré-modernidade, onde o afastamento e ausência do mundo globalizado são reais. Neste sentido, observa-se que em Tapauá ocorre o inverso da urbanização, ou seja, não foi a cidade que avançou para o campo, mas o campo que ocupou a cidade e, desta forma, não houve a completa urbanização, mas, pelo contrário, houve a completa ruralização. 
Pelas normativas jurídicas, urbano e rural são classificados pelo quantitativo humano; se baixa densidade, rural; à medida que aumenta o contingente populacional, se torna urbano. Porém, Veiga $(2004,2006)$ sugere como variável para nova classificação do urbano e rural, o grau de antropização, estimando que quanto menos habitado, maior será a preservação dos recursos naturais e o nível de poluição menor. Considerando que a densidade demográfica de Tapauá correspondente a 0,24 habitantes por $\mathrm{km}^{2}$, somada ao número de áreas protegidas e características naturais, pelo predomínio da várzea, pode se notar o reduzido grau de antropização. Assim, tomando por base a variável antropização, o município seria concebido como uma vasta área rural. As imagens a seguir retratam o cenário pouco antropizado no município.

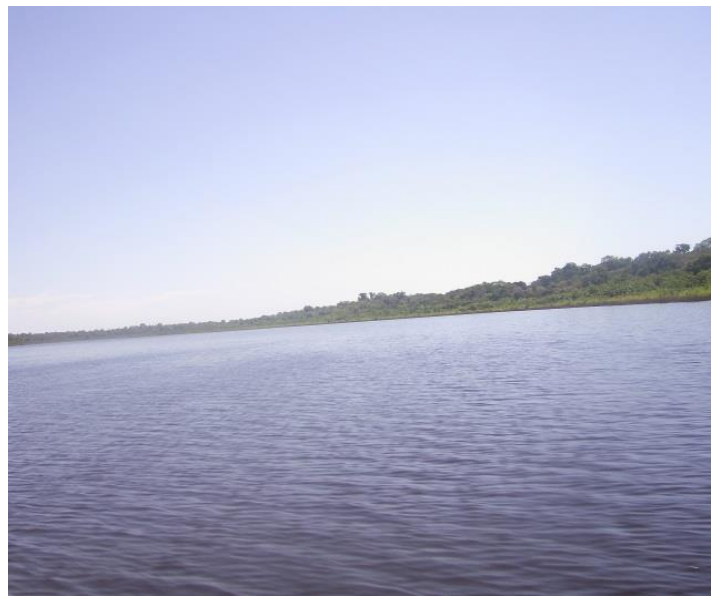

Figura 9: Área rural do município de Tapauá. Fonte: Pesquisa de Campo (2008).

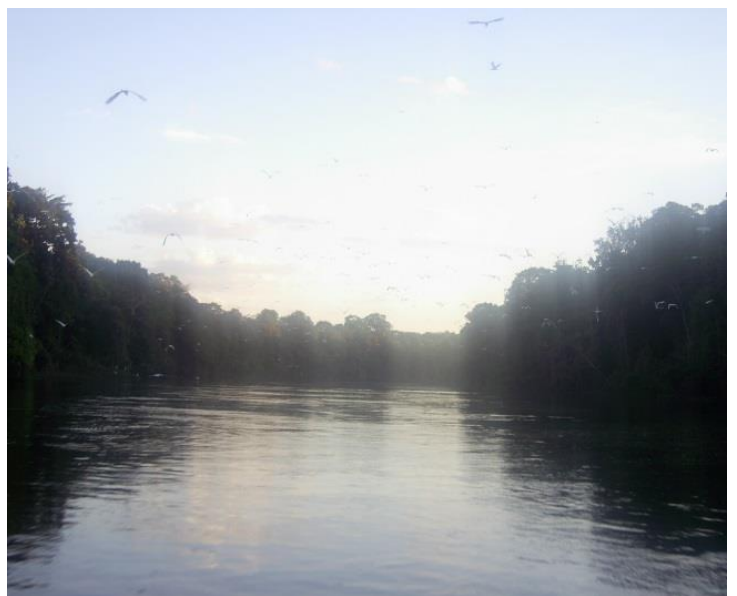

Figura 10: Área da reserva biológica em Tapauá Fonte: Pesquisa de Campo (2008).

$\mathrm{Na}$ área rural do município, é possível percorrer longas distâncias sem avistar uma moradia. Ainda, se aplicado o critério utilizado pela OCDE, que considera urbana a cidade com densidade demográfica superior a 150 habitantes por $\mathrm{km}^{2}$, Tapauá fica longe de ser considerada urbana. Mesmo a capital do Estado, Manaus, com densidade de 123,06 hab. $/ \mathrm{km}^{2}$, não se enquadraria.

Tapauá vive isoladamente; não há o que se denomina de urbanização expansiva, ideológica e urbanidade (Montemór, 2003; Lefebvre, 1991; Wanderley, 2001). Portanto, compreender o modo de vida como urbanismo por uma matriz teórica da cidade, tornase um desafio, sobretudo, porque o rural que se trata enquanto transcorrido, faz parte do presente em Tapauá: 
O que era o meio rural? Era o campo, o 'rústico', as relações familiares e de compadrio nas fazendas e propriedades agrícolas de tamanhos diversos, na maioria apoiadas em relações de produção pré-capitalistas, familiares e/ou servis - parceiros, meeiros, colonos, agregados, entre outros. [...]. Assim, o meio rural era também o espaço do coronelismo, do analfabetismo, da ausência de serviços coletivos e dos sistemas de energia, transportes, e comunicações, do não-acesso aos bens industriais modernos - grosso modo, o arcaico, o não-moderno, o território do isolamento e o espaço da não-política. (Montemór, 2003: 11).

Sua realidade se distancia ainda mais da classificação de urbano quando aplicado o critério utilizado pela União Européia, onde se adota a densidade superior a 500 mil habitantes ou o mínimo de 50 mil pessoas no município para se definir como urbano. Especificamente na Itália e na Espanha, se considera urbana a cidade com população superior a 10 mil habitantes e, em Tapauá, este teto ainda é inferior.

O Chile adota o total superior a 50\% da mão-de-obra ocupada em atividade não agrícola, o que não corresponde à realidade de Tapauá. As atividades socioeconômicas desenvolvidas pelos moradores da cidade representam mais uma característica do meio rural, estão diretamente ligadas às atividades primárias, como a pesca, agricultura, extrativismo e criação de aves, como galinha e pato.

Como se vê, os critérios metodológicos utilizados em outros países para definição de urbano, como densidade demográfica, total da população residente, ocupação da mão-de-obra e grau de antropização, se empregados a Tapauá, não a classificariam como urbano, se enquadrando somente nos critérios técnicos legais vigentes no Brasil.

Portanto, nenhuma metodologia distinta da brasileira colocaria Tapauá como urbano, sendo urbana ou cidade somente pelo critério administrativo vigente neste país há várias décadas.

Assim como as metodologias descritas não se aplicam à realidade da cidade, o modo de vida também representa uma prática rural. Considerando que estes moradores partem do meio rural para viver na cidade, não são motivados por atração à vida urbana ou interesse econômico que provocam o êxodo rural. 


\section{Considerações finais}

Este trabalho traz como contribuição a reflexão acerca da tipologia de cidade e definição do urbano na Amazônia. No Brasil, o que define cidade é uma normativa legal que data, ainda, do período militar. Esta considera toda sede municipal cidade, independentemente de qualquer variável, não importando tamanho, localização ou qualquer outro critério que considere sua especificidade. Por outro lado, o IBGE classifica como urbano a cidade. Esta normativa se difere de todos os demais critérios utilizados em outros países, que consideram o número de habitantes, densidade demográfica, por exemplo.

Desta forma, em cada região do país se apresenta uma tipologia de cidade, com tamanho variado e modo de vida específico. Na Amazônia, esta normativa aponta a necessidade de uma nova abordagem metodológica que dê conta da realidade empírica presente nas cidades amazônicas.

Considerando a singularidade da Amazônia, como única em suas características, não existindo em nenhum outro lugar do mundo uma região semelhante, esta se destaca pela sua dinâmica social, cultural e ambiental, sobretudo, no que se refere à interação dos seus habitantes com os recursos naturais.

Embora esta singularidade seja há décadas mencionada, na prática, não se mostra reconhecida no que diz respeito ao trato com as especificidades locais. Tais especificidades possibilitam afirmar que não é possível compreender a Amazônia sem o conhecimento empírico. Isto porque cada local retrata uma realidade, um modo de vida, expresso no cotidiano de seus habitantes e ainda ignorado pelas políticas públicas.

O caso específico de Tapauá demonstra o quanto a singularidade do lugar influencia na dinâmica de vida dos moradores. A diversidade e quantidade dos recursos naturais fazem com que estes moradores se locomovam dentro do território de acordo com a sazonalidade do rio. Diante da imensidão territorial, o morador torna-se possuidor do seu trabalho, do trato com natureza e, assim, pode realizar seus afazeres em qualquer lugar no município, não importando estar na cidade ou no campo.

Estas atividades são realizadas a partir de um tempo que é regido pelo tempo ecológico, determinando, assim, o horário e local para pescar, plantar e caçar. Utiliza como espaço para o plantio a terra firme, a várzea e a praia. A pesca pode ser praticada no rio, no lago e no igapó. 
A dinâmica ambiental também impõe a restrição ao espaço. Assim, o perímetro urbano não pode se expandir, devido à existência de uma Terra Indígena no seu limite. Desta forma, o crescimento de cidade fica restrito até mesmo na perspectiva populacional, devido ao alto custo imobiliário.

Diante desta restrição, mantendo-se pequena, a cidade se amplia apenas para dentro do rio, possibilitando a prática das atividades rurais, mantendo assim sua interação com os recursos naturais, característica que remete a um modo de vida rural.

Portanto, pensar cidade, urbano e rural na Amazônia significa pensar em meio ambiente e interação social articulada e forjada por ele. Tapauá é a prova empírica disso.

\section{Referências}

ABRAMOVAY, Ricardo. Funções e medidas da ruralidade no desenvolvimento contemporâneo. Texto para discussão n.702, FEA/Procam/USP: 2000.

BOURDIEU, Pierre. Gostos de classe e estilos de vida. In: Ortiz, R. (Org.). Coleção Grandes Cientistas Sociais, n.39. São Paulo: Ática, 1983.

FUNDO DE POPULAÇÕES DAS NAÇÕES UNIDAS (UNFPA). Relatório sobre a situação da população mundial, 2005.

GRAZIANO DA SILVA, José. Velhos e novos mitos do rural brasileiro. Estudos Avançados, São Paulo, v. 1, n. 43, p.43-50, 2001.

HUGUENIN, Fernanda Pacheco da Silva. O desencaixe moderno: o "tempo ecológico" de populações tradicionais. Vértices, Niterói, v. 7, n. 1, p. 27-36, 2005.

LAKATOS, Eva Maria. Técnicas de pesquisa: planejamento e execução de pesquisas, amostragens e técnicas de pesquisa, elaboração, análise e interpretação de dados. 6. ed. São Paulo: Atlas, 1996.

LEFEBVRE, Henri. O Direito à Cidade. Trad. Rubens Eduardo de Farias. São Paulo: Moraes Ltda, 1991.

LIMONAD, Ester. Reflexões sobre o espaço, o urbano e a urbanização. GEOgraphia, ano I, n. $1,1999$.

LIMA, Deborah; ALENCAR, Edna Ferreira. A lembrança da História: memória social, ambiente e identidade na várzea do Médio Solimões. Lusotopie, p. 27-48, 2001.

MINAYO, Maria Cecília de Souza. Pesquisa Social: teoria, método e criatividade. 6 ed. Petrópolis: Vozes, 1996.

MARQUES, Juliana Di Cesare Margini; SOUZA, Carlos Leite de. Cluster como instrumento estratégico de regeneração urbana sustentável. Cad. de Pós-Graduação em Arquit. e Urb., São Paulo, v.4, n.1, p. 59-72, 2004.

MEDEIROS, Rodrigo Jesus de. A Proteção da Natureza: das Estratégias Internacionais e Nacionais às demandas Locais. Rio de Janeiro, 2003, 391p. Tese (Doutorado em Geografia). Rio de Janeiro: UFRJ/PPG. 2003.

MONTE-MÓR, Roberto Luís. Urbanização Extensiva e Novas Fronteiras Urbanas no Brasil. In E. Rassi Neto \& C. M. Bógus (Eds.). Saúde nos Grandes Aglomerados Urbanos: uma visão integrada (Vol. 3, pp. 79-95). Brasília, DF: Organização Mundial de Saúde (OMS): Organização Pan-Americana de Saúde (OPAS); Ministério da Saúde, Brasil. 2003. 
RÉGNIER, Jean-Claude; FALCÃO, Jorge Tarcísio da Rocha. Sobre os métodos quantitativos na pesquisa em ciências humanas: riscos e benefícios para o pesquisador. Revista Brasileira de Estudos Pedagógicos, v. 81, n. 198, p. 229-243, 2000.

SANTILLI, Juliana. Biodiversidade e conhecimentos tradicionais associados: novos avanços e impasses na criação de regimes legais de proteção. Revista de Direito Ambiental, São Paulo: Revista dos Tribunais, n.29, 2003.

VEIGA, José Eli da. A atualidade da contradição urbano-rural. In: SUPERINTENDÊNCIA DE ESTUDOS ECONÔMICOS E SOCIAIS DA BAHIA (Org.). Análise Territorial da Bahia Rural. Série de estudos avançados, n. 71, Salvador: SEI, 2004.

. Nascimento de outra ruralidade. Estudos Avançados, São Paulo: USP/IEA, v. 20, n. 57, p. 333-353, 2006.

WANDERLEY, Maria de Nazareth Baudel. A emergência de uma nova ruralidade nas sociedades modernas avançadas - o "rural" como espaço singular e ator coletivo. Estudos Sociedades e Agricultura, n. 15, p. 87-146, out. 2001.

WIRTH, Louis. O Urbanismo como modo de vida. Trad. Marina Corrêa Treuherz. In: VELHO, Otávio Guilherme. O Fenômeno Urbano. Rio de Janeiro: Guanabara, 1987.

YIN, Robert. K. Estudo de caso: planejamento e método. São Paulo: Bookman, 2005.

Recebido em: 03/11/2015.

Aprovado em: 30/03/2016. 